\title{
Managing Complex Work Systems via Crowdworking Platforms: How Deutsche Bank Explores AI Trends and the Future of Banking with Jovoto
}

\author{
Volkmar Mrass \\ University of Kassel \\ volkmar.mrass@uni-kassel.de
}

\author{
Christoph Peters \\ University of St.Gallen \\ and University of Kassel \\ christoph.peters@unisg.ch
}

\author{
Jan Marco Leimeister \\ University of St.Gallen \\ and University of Kassel \\ janmarco.leimeister@unisg.ch
}

\begin{abstract}
Crowdsourcing has evolved into a powerful new instrument for companies. In the last years, crowdworking platforms that manage work systems as intermediaries between crowdsourcers and crowd workers have increasingly been used. Nevertheless, they currently often manage rather simple work systems. Although they have the potential for managing more complex ones, there is still little knowledge how this can be done and what measures are necessary to do so. To explore this question in more detail, we investigate three seminal projects that Deutsche Bank completed with the crowdworking platform Jovoto and that aimed at exploring AI trends and developing concepts for the future of banking. We derive measures necessary for the successful management of complex work systems and provide a model as guidance for both companies and crowdworking platform operators. With our findings, we extend current knowledge in the realm of IS, organizational theory, and platform ecosystems.
\end{abstract}

\section{Introduction}

The digitization of economy and society has gained momentum in the last years and is continuing to proceed. The competitiveness of whole countries, economies, branches and corporations depends on how successfully they are able to adapt to the present changes [10]. One important development in the area of digitization of work in the last decade is crowd work, a new form how to organize the division of labor in a digital environment. It introduces a paradigmatic change: Work does not get assigned anymore; instead, workers choose their work themselves [12]. Crowdworking platforms as intermediaries between crowdsourcing companies and crowd workers play a crucial role in this context. Despite their increased economical importance, many aspects regarding crowdworking platforms have not been investigated by the IS community intensively so far. This is especially true regarding the management of complex work systems via such platforms. Existing contributions about crowdworking platforms from the IS area often focus on microtask platforms with their usually relatively simple [6], low-paid [9] work.

Taking into account the advancing digitization of work and society, the authors of this paper believe that there are at least three major reasons to explore how complex work systems can be managed via crowdworking platfoms: Firstly, the technological development that will lead to increased "computerisation" of jobs (see e.g. [5], [3]). This makes it also more likely that rather simple work currently performed by humans on such platforms will be automatized. Secondly, many crowdworking platforms are increasingly coming "under scrutiny" since several societal players (see e.g. [2]) have started discussions about fair working conditions, "new Taylorism" or minimum wages. Processing more complex work would allow to pay higher wages and to meet potential future requirements which might be imposed by legislators. Thirdly, this business model simply offers more potential for the processing of work than it is currently the case. For example, an investigation of 32 crowdworking platforms [11] in Europe's largest economy, Germany, showed that the majority of them focuses on work such as collecting data from the point of sale (POS), designing t-shirts, microtasking, testing devices and software, writing short texts, or the like. Using the potential of crowdworking also for the management of more complex work would be a natural further development of their business model and would make such platforms even more attractive to companies.

All reasons mentioned above serve us as a motivation to investigate how complex work systems can be managed via crowdworking platforms. We believe that the complexity of work is as a good proxy for the complexity of a work system necessary to process that work and that both are highly correlated. Research regarding this topic is important for the future success of crowdworking platforms as a digital innovation of the last decade. We position our research in the realm of IS and organizational theory, especially in the relatively new area of platform ecosystems. We aim at contributing to this 
realm and extending current knowledge by exploring measures for the successful processing of complex work systems via crowdworking platforms. To do so, we look at this issue on a more "macro-level", using the lense of work system theory (WST) [1] and investigating the interplay of participants, information and technologies to perform processes and activities with the aim to deliver products and services to the customers. To get insights about the management of complex work systems via crowdworking platforms, we have chosen to investigate in detail three seminal projects the financial services provider Deutsche Bank conducted with the crowdworking platform Jovoto. In this paper, we pursue the following research question:

RQ: How can complex work systems successfully be managed via crowdworking platforms?

After this introduction, the paper proceeds as follows: First, we provide a foundational theoretical background. Second, we describe the research methodology and case selection for the conduction of our research. Third, we introduce Deutsche Bank and Jovoto and their three seminal projects. Fourth, we analyze the work system, communicate our findings and insights regarding the management of complex work systems via crowdworking platforms that we gained and develop our model. Finally, we close with a discussion and a conclusion of our research.

\section{Theoretical Background}

Crowdsourcing platforms can be seen as intermediaries and in general the point where the controlling and management of the crowd and of all activities within the crowd take place [8]. If these platforms focus on the performance of paid work (in contrast for example to platforms for fundraising or voting), it is reasonable to use the term crowdworking platforms ([13], [14]) as a subset of crowdsourcing platforms. In organizational environments, work is "the application of human, informational, physical, and other resources to produce products/services" ([1], p. 75). Complex work is for the authors of this paper - derived from the description of characteristics of simple work on a microtask platform by Kittur et al. [6] and reversing these - in general work that mostly requires coordination, a high level of cognitive effort, expertise and skills in the respective area, time and contextual information; it is usually heterogeneous, interdependent, rather non-repetitive and has multiple stakeholders. The World Bank uses in a study [7] skills and education or training required as a proxy to determine work complexity. It assigns low complexity to microwork where mostly no specialized skills or training are required and basic computer and Internet literacy (and the associated language) skills are usually sufficient. It attributes high complexity ([7], p. 13) to work from areas such as engineering, software development or human resources. Sometimes, the terms work and task are used synonymously. In our research, we use the term "task" for a rather limited and narrow "to do" that is more likely (even though not necessarily) to be done by an individual without too much interaction with others. We use the term "work" as something that has a more holistic nature and is more likely to require collaboration, coordination and interaction with others.

A work system is "a system in which human participants and/or machines perform work (processes and activities) using information, technology, and other resources to produce specific products/services for specific internal and/or external customers" ([1], p. 75). In our case, participants of the work system are first of all the crowd workers (of Jovoto), but often also customer representatives (of Deutsche Bank) if they participate in the creation of the products and services and internal employees of the platform operator. Information refers to informational entities such as orders or invoices as well as to conversations and verbal commitments by the work system participants ([1], p.80). Technologies include both tools that are used by work system participants and automated agents (i.e. hardware and software configurations) since some work systems are totally automated (ibidem). Processes and activities occur in the work system to create products and services for its customers. Besides the elements of the work system itself described above, the Work System Framework ([1], p. 78) also includes environment, infrastructure and strategies. As already mentioned in the introduction, the complexity of work is a good proxy for the complexity of the work system necessary to process this work. With our research, we are looking at IT-reliant work systems; more specifically, at work systems that are managed via crowdworking platforms. We purposefully mostly use the term "manage" (in the sense of planning/steering/controlling) instead of "govern" since the landscape of crowdworking platforms is heterogeneous and some platforms are more coordinating the supply and demand than governing the whole work system (although the term govern would be accurate in many cases).

\section{Methodology and Case Selection}

With our research question, we pursue an issue eminent for the future development of the business model of crowdworking platforms. Since this question is a "how?"-question, we employ the research method 'case study' that according to Yin [15] is especially adequate and useful for such research questions. Investigating the unit of analysis of our research - the work system consisting of processes and activities, participants, information and technologies - aims at providing valuable 
insights and sheding light on this issue. According to Eisenhardt [4], the case study is a research strategy that focuses on understanding the dynamics present within single settings. Case studies can be used to accomplish various aims: to provide description, test theory, or generate theory [4]. Our interest in this paper points on the first and third aim: to provide description and subsequently derive a model for the management of complex work systems via crowdworking platforms. According to Yin [15], the case study research method is in general especially useful when (1) the main research questions are "how" or "why" questions, (2) a researcher has little or no control over behavioral events and (3) the focus of study is a contemporary (not entirely historical) phenomenon. This is true regarding our investigation: With our research question, we strive to examine how complex work systems can be managed via crowdworking platforms; we have no influence on behavioral events since we do not interfere in the interactions between crowdsourcers, platforms and crowd workers and the focus of our study, crowdworking platforms, are a current phenomenon and not something from the past. In order to realize triangulation and thereby providing a stronger substantiation of constructs and hypotheses as suggested by Eisenhardt [4], we used the following multiple sources to collect data for this case study:

- In-depth interviews with Bastian Unterberg, the Chief Executive Officer (CEO) of Jovoto (on July $19^{\text {th }}, 2016$, and June $1^{\text {st }}, 2017$ )

- Several contacts with and information from employees of Jovoto (February to May 2017)

- Analysis of the publicly available information (e.g. press) about the projects (March to June 2017)

- Intense analysis of the information available on Deutsche Bank's and Jovoto's Internet websites (May 2017)

- Evaluation of additional material received from Jovoto after the interviews with CEO Unterberg. For the semi-structured interviews, we developed a guideline with questions addressing different areas of the work system (e.g. measures for the steering of the participants, the planing of the processes/activities, the design of the platform/technology etc.) to get insights from different perspectives on the theme of managing complex work systems via crowdworking platforms such as Jovoto. The interviews were recorded and subsequently transcribed. A draft of the resulting paper has been delivered to the interviewee to offer the possibility to comment it or request adjustments if necessary.

To be able to generate the desired insights, we chose a crowdworking platform that:

- Deals with the management of complex work (systems) as defined in section 2

- Is positioned on an international basis, i.e., has crowd workers and customers from all over the world (to ease comparability and the application of the findings on an international level)

- Has already been existing for a while (i.e., at least three years) and shows a good business record (i.e., growing revenues), therefore making it more likely that it has gained enough expertise to answer our questions regarding the management of complex work systems adequately and that we are able to study its development also in the future

- Has conducted projects that have been very successful (to be able to generate useful recommendations for projects of other companies and platforms).

We selected the crowdworking platform "Jovoto" since its provider manages plenty of complex work systems. Jovoto also enables the management of both external and internal (employees of a company) crowds on its platform - a measure that we identified as one key measure for the successful management of complex work systems via crowdworking platforms in our earlier research. The platform is furthermore not restricted to the use in a specific company (which is the case with several proprietary platforms), but open to companies worldwide that want to use its services. Despite the fact that the area of crowdworking companies is dynamic and many companies that existed years ago do not exist anymore (e.g. because they merged with other companies or went bankrupt), Jovoto has already been on the market for about a decade (since 2007), has strongly increased its revenues, and proved to be able to "survive" in the long term. Moreover, the areas of financial services and innovation services are in general areas that require the management of more complex work systems than it is for example the case with microtask platforms. Therefore, the examination of the projects managed via the crowdworking platform Jovoto with Deutsche Bank proved to be valuable to answer our research question.

\section{The Case of Deutsche Bank and Jovoto}

\subsection{Company Profiles}

Deutsche Bank is Germany's leading bank and with a balance sheet total of 1.59 billion Euro also among the largest banks in the world. Founded in 1870 in Berlin and since 1957 headquartered in Frankfurt am Main, the company employs 99.744 people and runs 2.656 branches (see also: www.db.com/company/company.htm). Deutsche Bank is present in over 70 countries worldwide, including major financial hubs such as London, New York, Hong Kong, Singapore or Zurich. Structured around the three types of clients it serves in the areas "Private \& Commercial Bank", "Deutsche Asset Management" and "Coporate \& Investment Bank" 
(see also: www.db.com/company/en/what-we-do.htm), this universal bank belongs to the global market leaders in several realms (e.g. foreign exchange transactions) and is according to the Financial Stability Board one of the six global systemically most important banks (see also: www.fsb.org).

Jovoto is a design and innovation crowdworking platform with more than 80,000 creative crowd workers from 153 countries all over the world. Founded in Berlin in 2007 where it is also headquartered, the company has organized more than 400 creative contests ("crowdstorms") for large brands and NGO's since then (see also: www.jovoto.com/about/). It's 33 internal members team is based in Berlin (headquarters) and in addition runs a subsidiary in the US. The services Jovoto manages via its crowdworking platform range from product design and marketing campaigns to innovative business scenarios of the future.

\subsection{Initial situation}

As one of the global market leaders, Deutsche Bank had already early sensed the impact of digitization on banking and its own business model. One action the company took to explore the effects and opportunities of this development is to cooperate with the crowdworking platform Jovoto. The institute realized that digitization not only results in innovations that will have a huge impact on its own business model, but also that it has the potential for creating new business models. In particular, that digitization will alter the service interface between Deutsche Bank and its customers, especially in the realm of private banking and retail banking. And that it is therefore paramount for Deutsche Bank to start early to prepare. The company therefore aimed at exploring the advices of a diverse range of crowd workers such as developers, service designers, product designers and (UX) designers.

"The digital world is driving changes in banking at great speed - working with jovoto and open innovation helps us stay agile by screening innovative ideas on a global scale in a short amount of time."

Markus Pertlwieser, Chief Digital Officer

Private, Wealth and Commercial Clients (PW\&CC) at Deutsche Bank

\subsection{The three projects}

Between December 2015 and October 2016, Deutsche Bank and Jovoto conducted three projects together under the label "The Future of Banking" (see also: www.jovoto.com/creative-hubs/future-of-banking). The first two projects have been conducted as "private" projects, meaning that participation has been re- stricted among others for data security and quality reasons to only a part of the crowd (the top 10 percent of Jovoto's crowd). The third project has been conducted as an "open" project, meaning that the whole crowd of more than 80,000 creatives was allowed to participate.

For the first project, Jovoto's crowd had to develop an outstanding customer experience for Deutsche Bank's premium customers, including integrated services and tools (see also: www.jovoto.com/projects/progressive-premium/landing). The aim of this project was to build the "the best and most sustainable customer experience in banking - as digital as necessary, as human as possible". The goal was not only to create new digital tools and services for its premium customers with significant financial assets and high expectations regarding services, but also to integrate them into existing channels and to combine them with competent personal advisory services. The main target group within the Jovoto crowd to tackle this challenge have been fintech experts and service designers. The crowd had eight weeks to work on their proposals that afterwards have been judged among others by a jury consisting of 10 members from business, the customer Deutsche Bank and science. The more than 7,000 participants from 30 countries generated over 240 concepts that received more than 1,200 comments that helped to further develop these concepts. Deutsche Bank awarded a total of 25,000 Euro to 15 winners within different categories of this project. The winners of the jury's judgements have been awarded at a ceremony on April $11^{\text {th }}, 2016$, at the location "Deutsche Bank of the Future/Q110" in Berlin. The generated service design solutions during the project ranged from the realms of artificial intelligence and big data over enablement advisors to services for younger target groups. Six selected members of the Jovoto crowd got the opportunity to refine their concepts together with experts from Deutsche Bank and external consultants at Deutsche Bank Innovation Lab in Berlin during the next four days following the award ceremony. The company was satisfied with the results generated during this project:

"Crowdstorming is a new concept for Deutsche Bank. This exchange enables us to generate out-of-thebox ideas for our innovation process, in order to remain relevant for our customers in a constantly changing world."

Mirjam Pütz, Head of Disruptive \& Strategic Programs, Deutsche Bank

During the first project described above, several ideas from the realm of artificial intelligence (AI) emerged. This led to the idea of the conduction of a separate second project that demanded Jovoto's crowd to share their vision of how artificial intelligence (AI) can help reinvent Deutsche Bank's customer service experience (see also: www.jovoto.com/projects/artificially- 
enhanced-banking/landing). Especially to consider the role of $\mathrm{AI}$ in the future of banking given that $\mathrm{AI}$ is widely regarded as a decisive area and many companies are investing heavily in research and development activities in this realm. Jovoto's crowd was aimed to explore how AI trends could be exploited for banking and to discover ideas that could be "game changers" for the banking industry in the future. The submission period of the project ended on June $28^{\text {th }}, 2016$. Again, Deutsche Bank awarded a total of 25,000 Euro, this time to 25 winners within different categories of the project. There have also been two awards for the crowd workers who submitted the best ideas during the first half of the project time: A journey to a TEDx event of their choice. Again, a jury (consisting of members from business, science and the customer) examined the work and some of Jovoto's crowd workers have been invited to further develop their concepts during a three-day workshop with experts at the Deutsche Bank innovation labs in Berlin.

The third project aimed at creating a blockbuster film script and poster ("The Digital Leader"), targeting the employees of Deutsche Bank to help to push digital transformation at the company itself (see also: www.jovoto.com/projects/follow-the-leader/landing). It took place in view of the fact that digital tranformation processes present several challenges especially for established, longstanding organizations. Currently, players such as Deutsche Bank face challenges from several new competitors - including fintech startups and tech giants who enter the financial industry. Since these challenges request for digital leaders, the goal has been to contribute to putting digital thinking at the heart of
Deutsche Bank's business, to get all staff "on board" and make them play an active role in this "journey". In this project, Jovoto used the services of an additional freelancer (an expert filmmaker and creative director) as "creative guide" to provide additional advices and moderate the project. The submission period ended on September $27^{\text {th }}, 2016$. There have again been two "halftimeawards": An iPad Pro and a one-year subscription of Netflix. The four-person jury from business, the customer Deutsche Bank and science rewarded three prizes worth 3,000 Euro each. In addition, there have been twelve community prizes ranging from 1,000 to 100 Euro each, and several smaller awards of 300 respectively 200 Euro each for "best collaboration", "best feedback", "fairest rater" and "newcomer". Deutsche Bank awarded a total of 15,000 Euro to 17 winners.

"It's no longer about the digitalisation of the banking business, but about the future of banking in a digitalised world."

Christian Sewing, Head of Private \& Commercial

Bank (including Postbank) and member of the Management Board of Deutsche Bank

On the whole, Deutsche Bank awarded 65,000 Euro directly to 57 winners in these three "Future of Banking"-projects in addition to half-time awards, the remuneration for the crowdworking platform Jovoto itself and remuneration for licencing concepts that Deutsche Bank aimed to develop further.

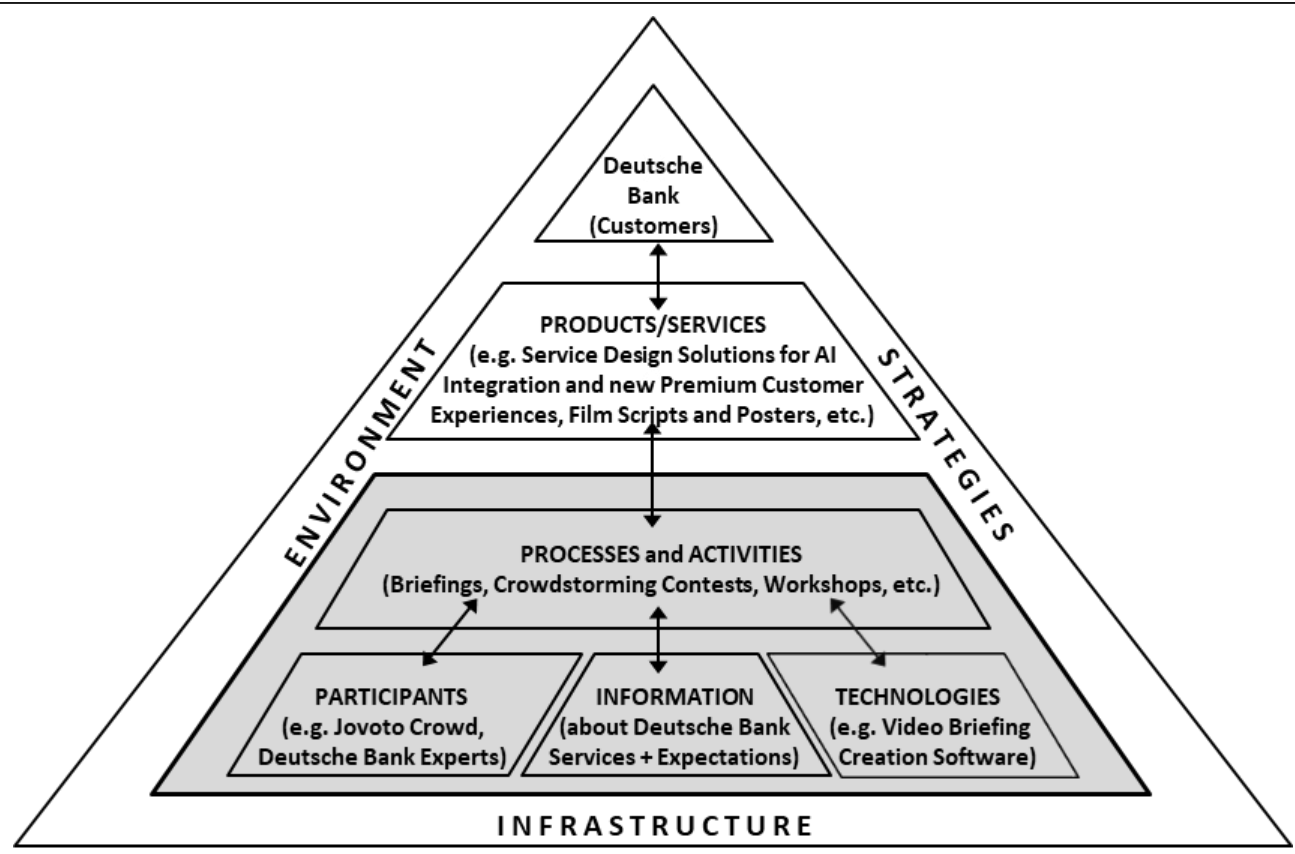

Figure 1. Depiction of the Deuts che Bank \& Jovoto Work System based on Alter ([1], p. 78) 


\section{$5 \quad$ Findings and Insights}

\subsection{Analysis of the work system}

Drawing on Alter's Work System Framework ([1], p. 78 ) introduced in section 2 , we first analyzed the whole work system of Deutsche Bank and Jovoto. This analysis served us as a basis to better understand the interplay between participants, information and technologies to conduct processes and activities. It also sharpened our own view of which parts belong directly to this work system and which are surrounding elements. This basic analysis also helped us to examine in detail the diverse processes and activities conducted during the three projects described in section 4.3. Figure 1 above depicts the work system framework of Deutsche Bank and Jovoto.

\subsection{General main steps in the process}

Our analysis of the projects with Deutsche Bank showed the following general approach how Jovoto tackles the management of complex work systems (see also: www.jovoto.com/how-it-works): In the first step, the customer creates a short briefing together with Jovoto. This is paramount to allow both Jovoto and its crowd to better grasp the character of the challenge. Jovoto's expert creative crowd strategists help the customer in this step to create a compelling briefing that appeals to the best creatives and paves the way for a successful processing. The briefing usually consists of background information, the description of the assignment, the remuneration, as well as visualizations such as videos to inspire the Jovoto crowd. The second step is the decision about the type of project conduction: "Public" (all > 80,000 Jovoto crowd workers can participate with the effect of the widest possible range of results and the highest brand engagement and social reach), "private" (open only to the "top ten percent" of Jovoto's crowd, generating the qualitatively highest results, and with the option to sign non-disclosure agreements/NDA's) to keep the project hidden from competitors) or "flex" (a tailored pool of participants including the possibility to select a specific demographic group within the Jovoto crowd or to integrate own employees). In the third step, Jovoto releases the contest on its crowdworking platform and the creative working pro- cess starts. The customer company can follow this process in realtime and observe how collaboration including challenges and feedbacks take place. Finally, in the fourth step, the customer receives the results generated by the Jovoto crowd and the remuneration is concluded. Figure 2 below visualizes these main process steps.

\subsection{Specific steps in the premium customer ex- perience project}

Figure 3 depicts the steps for the management of complex work systems via crowdworking platform Jovoto on a more specific level, using the first of the three projects Deutsche Bank conducted with Jovoto (the premium customer experience project). It also serves as a basis for the succeeding section 5.4 where we describe the development of the model for the management of complex work systems via crowdworking platforms.

\subsection{The "Complex Work Systems Model"}

In this section, we describe in detail how we developed the "model for the management of complex work systems via crowdworking platforms" that can serve as a basis for both companies who want to utilize crowdworking platforms for the processing of their work and crowdworking platform operators. We will do this in the following way: We describe what measures have been taken when managing the work systems in the projects of Deutsche Bank and Jovoto and then derive the respective recommendations, explain them and include them into the model. In doing so, we follow Yin ([15], p. 57) who states that one of the reasons for choosing the "classic" single-case study design is the revelatory aspect (since such studies can shed light on an underinvestigated issue). The following measures are the derived key measures for the successful management of complex works systems via crowdworking platforms:

Briefing and requirements elicitation. Deutsche Bank and Jovoto closely worked together to develop scope, requirements and conditions for the project. They also defined the process in detail. Later, this briefing was announced to the crowd via the platform.

-> Measure: Clear definition of the requirements, the process and the scope of a project together with the customer and delivery of the briefing to the crowd.

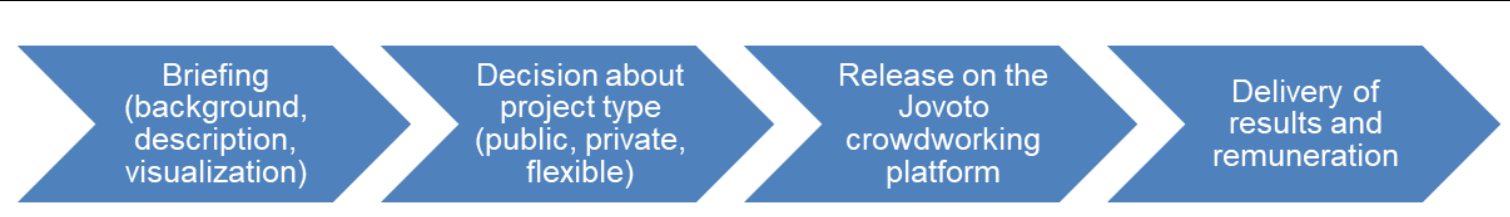

Figure 2. General steps in the work system management of Jovoto (source: own depiction) 
Suitable work mode. With regard to complex work systems, Jovoto purposefully has no measures in place to divide work into smaller pieces and reassemble them. This might be appropriate for microtask platforms, but is according to Jovoto's experience not a useful measure when it comes to complex work systems. Regarding the work mode, customers of Jovoto have the choice to run a project as "private" (restricted participation), "public" (open participation) or "flexible" (participation by invitation only). Two of the projects with Deutsche Bank have been conducted as a private project, meaning that only the top ten percent of Jovoto's crowd of more than 80,000 that have been identified as "top talents" during former projects have been able to participate.

-> Measure: Possibility to conduct projects with different degrees of openness and target groups to be able to meet customer needs with regard to confidentiality, innovativeness, quality, or security.

Personal activation. Jovoto unlocks the crowd workers on their platform who are selected to participate (in the case of the first two projects with Deutsche Bank the "top ten percent" of the more than 80,000). They get a link where they can access the materials necessary to participate and create a solution. To activate them, the crowd workers also receive a personal welcome message (either automatized or manually) by the Jovoto community management team. In addition, Jovoto's "outreach-team" acquires and invites talented individuals outside of the Jovoto crowdworking platform. After the respective crowd worker has read the briefing, (s)he can decide if (s)he wants to participate.

-> Measure: Personal activation of the crowd workers from the own platform and in addition also contacting of further talented potential contributors from outside.

Financial and non-financial incentives. In the projects of Deutsche Bank and Jovoto, there have been both financial and non-financial incentives. Financial incentives included among others the on the whole 65,000

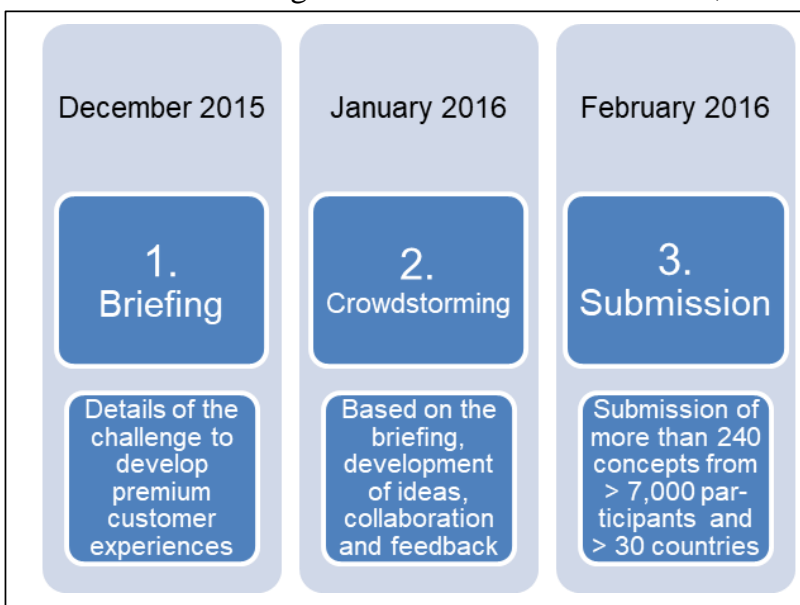

Euro that have been distributed by Deutsche Bank among 57 winners. In addition to the half-time awards such as iPad Pro or visit to an TEDx-event of one's choice that helped to manage process speed, non-financial incentives also played an important role: Among others the possibility for reputation building, to receive recognition and appreciation, gain visibility and grow personally. Furthermore, selected participants of the "premium customer experience project" have been invited to the Deutsche Bank Innovation Lab in Berlin that helped "building a bridge" to transform the concepts and ideas generated during the project into realized measures in the company.

-> Measure: Provision of both financial incentives (monetary rewards) and non-financial incentives such as the possibility to gain visibility, for example an invitation to a high-ranking audience of the customer.

Contracts (e.g. NDA's). In the case of the AI enhanced banking and the premium customer experience project, Deutsche Bank paid 25,000 Euro in prizes, respectively. The individual crowd worker remains the holder of the rights of the concept unless the customer Deutsche Bank decides to purchase these rights to further develop the concept. The crowd worker gives the exclusive right to Deutsche Bank to purchase the rights within the time span of six months. If the customer decides to further develop a concept generated in the respective project, there is an additional remuneration. In some cases, the remuneration amount in case of the acquisition of the rights by the customer is negotiated in advance. Jovoto uses law experts as "translators" between the world of corporations and the world of crowd workers who interact with both parties to help to secure a legally sound agreement. Agreements also include other legal areas such as for example NDAs.

-> Measure: Implementation of sound contracts to manage several legal areas such as non-disclosure or the transfer of author's rights, copy rights and related rights.

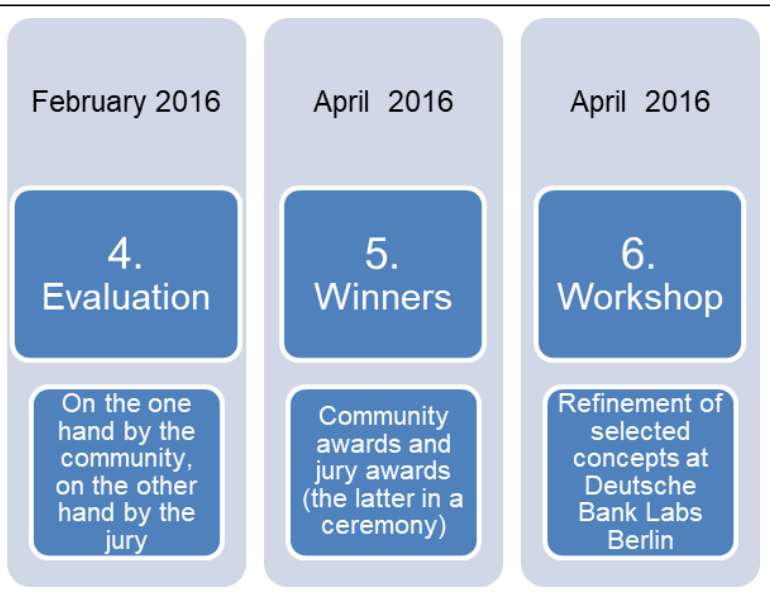

Figure 3. Specific steps in the premium cus tomer experience project (source: based on Jovoto) 
Provision of a halftime-feedback. In the halftime, Jovoto conducted a two-hours-video meeting with all experts and the customer representatives. In this meeting, there has been a discussion about the question which concepts are interesting and which possible customer interfaces with Deutsche Bank exist. The external experts communicated if they had seen similar successful ideas in other industries. This first "proof" including insights from external experts is important for Jovoto and its further management and steering of the work system. It ensures that Jovoto not only receives suggestions from its own crowd, but also from external, international experts that are renowned als leading experts in their field of expertise. This allows Jovoto to help its crowd to further sharpen their concepts/solutions and develop them in the direction of an "elevator pitch" between the halftime-feedback and the end of the project. This joint effort is according to Jovoto especially necessary to successfully manage complex work systems.

-> Measure: Provision of halftime-feedback to discuss the solutions gained so far with the crowd community, the customer and external experts as a basis for the refinement until the project end. This also allows to adapt or correct the direction in a rather early stadium.

Collaboration enhancement/community management. In addition to mere communication, Jovoto also fosters direct collaboration on its crowdworking platform. CEO Bastian Unterberg from Jovoto emphasizes that especially for complex work, it is necessary to have an interdisciplinary dialogue with a diverse set of crowd workers, to collaborate and cooperate, and even to team up if reasonable. Often, several crowd workers have similar ideas and are therefore approached by the Jovoto community management team with the question if they would like to join forces and work together. Especially if the respective crowd workers already know each other and have also worked together successfully in other projects, they often team up after such a suggestion. From the experience of Jovoto, these measures all contribute to a better solution and are especially useful when it comes to complex work.

-> Measure: Implementation of a community management team of the crowdworking platform to ensure cooperation and collaboration among the crowd workers.

Communication and feedback tools. The first ideas from the crowd on Jovoto's platform arrive in a rather rough form. They are then discussed by the crowd, the guide (see below), and sometimes also the customer (who has permanent access). In addition, Jovoto has created a committee of experts including representatives from business, science, and venture capitalists. All these parties give feedback, enabling the crowd workers to realize in an early stage if the respective concept has potential and is worth to be explored or if the concept should rather be discarded and replaced by a new one.
During the weeks the respective project runs, many ideas are discussed and these discussions lead to fruitful further developments, improvements and refinements. Communication usually takes place on the platform itself. Jovoto also offers the possibility to write private messages on their platform and provides communication possibilities such as webinars and video formats. -> Measure: Implementation of tools on the platform that foster fruitful communication and exchange among participants from the crowd, customers, external experts and guides to enhance the quality of the work.

Guidance by specialized experts. Especially with regard to complex work systems, Jovoto also employs guides to accompany and moderate processes and activities. They are either employees of Jovoto or - in cases where specific external expertise is necessary - hired freelancers from outside. Jovoto has a network in place from where it recruits external guides. In one of the projects with Deutsche Bank, there was the need for a person who has knowledge of service design, artificial intelligence and the finance area. Since these are rather special requirements, Jovoto hired an external freelancer for this project who had gained a lot of experience in this realm as a coach. The main mission of this person is to intermediate, moderate, stimulate, and not least manage the processes/activities. Because of his vast experience, younger talents are able to learn from this person. The person also has to have good soft skills.

-> Measure: Employment of a guide from either the internal team of the crowdworking platform provider or an external specialist for the accompaniment and moderation of the processes/activities in the work system.

Creation of an inclusive culture. Both Deutsche Bank and Jovoto put great emphasis on a constructive and inclusive culture. The team of Deutsche Bank for this project was highly able to deliver on the participation promise that was given to the crowd at the beginning. Deutsche Bank for example invited the winners of the customer premium services project to their "Q110 die Deutsche Bank der Zukunft" (Deutsche Bank of the Future)-location in Berlin for an award ceremony (including press). There, they expressed their appreciations and honor personally.

"One has left the virtual space and has encountered in the real world - this also had an impact. We make sure that our crowd and our customers both experience bilateral esteem and respect. Trust is the basis for our working model."

Bastian Unterberg, CEO of Jovoto

-> Measure: Establishment of a culture that fosters mutual respect and trust, including personal encounters between the customer and the crowd in the 'real world'.

Evaluation of the results. Another steering instrument in place is the evaluation of the concepts and re- 
sults after the end of the submission period. The evaluation took place by both the Jovoto crowd community that participated in this project and the jury of experts from business, the customer Deutsche Bank, science and venture capitalists. Feedback by the crowd community was given on different levels - for example, "who has been a good team player?", "who gave plenty of feedback?", "Who stimulated a lot of good ideas?", and more. All of these actions within the crowd community have been incentivized with monetary prizes. In addition, the concepts selected by the expert jury have also been incentivized with additional prizes.

-> Measure: Evaluation of the concepts and solutions by both the participating crowd community and an expert jury to ensure different perspectives and prizes that foster desired behavior on different levels.

Fostering the sustainability of business relations. At the end of the day, it is the customer who decides which concepts he wants to pursue and wants to implement. Which concepts these have been regarding the projects with Deutsche Bank is confidential information; in any case, Deutsche Bank and Jovoto regard these projects as very successful. Among others, the participation from the crowd has been high; the feedback of the customer has been very positive. Als already mentioned, the successful completion of the first project (premium customer experience) not only resulted in an idea for a second project (artificially enhanced banking), but also led to an increased participation in the latter. -> Measure: Design of the first project with a customer in a way that fosters subsequent projects (if the first has been successful) to create "win-win-situations"; followups after a project.

Figure 4 shows the derived model for the successful management of complex work systems of DB \& Jovoto.

\section{Discussion and Conclusion}

The question how complex work systems can successfully be managed via crowdworking platforms has not been investigated very intensively in IS research so far. Detailed knowledge about measures to do so is crucial for the future development of this novel form of work organization. Using a case study approach, we closely examined in this paper three seminal projects of Deutsche Bank with Jovoto, especially one with the focus on AI trends relevant for the future of banking, that included the management of complex work systems. We analyzed the respective work system consisting of the interplay between participants, information and technology to conduct processes/activities with the aim to de-

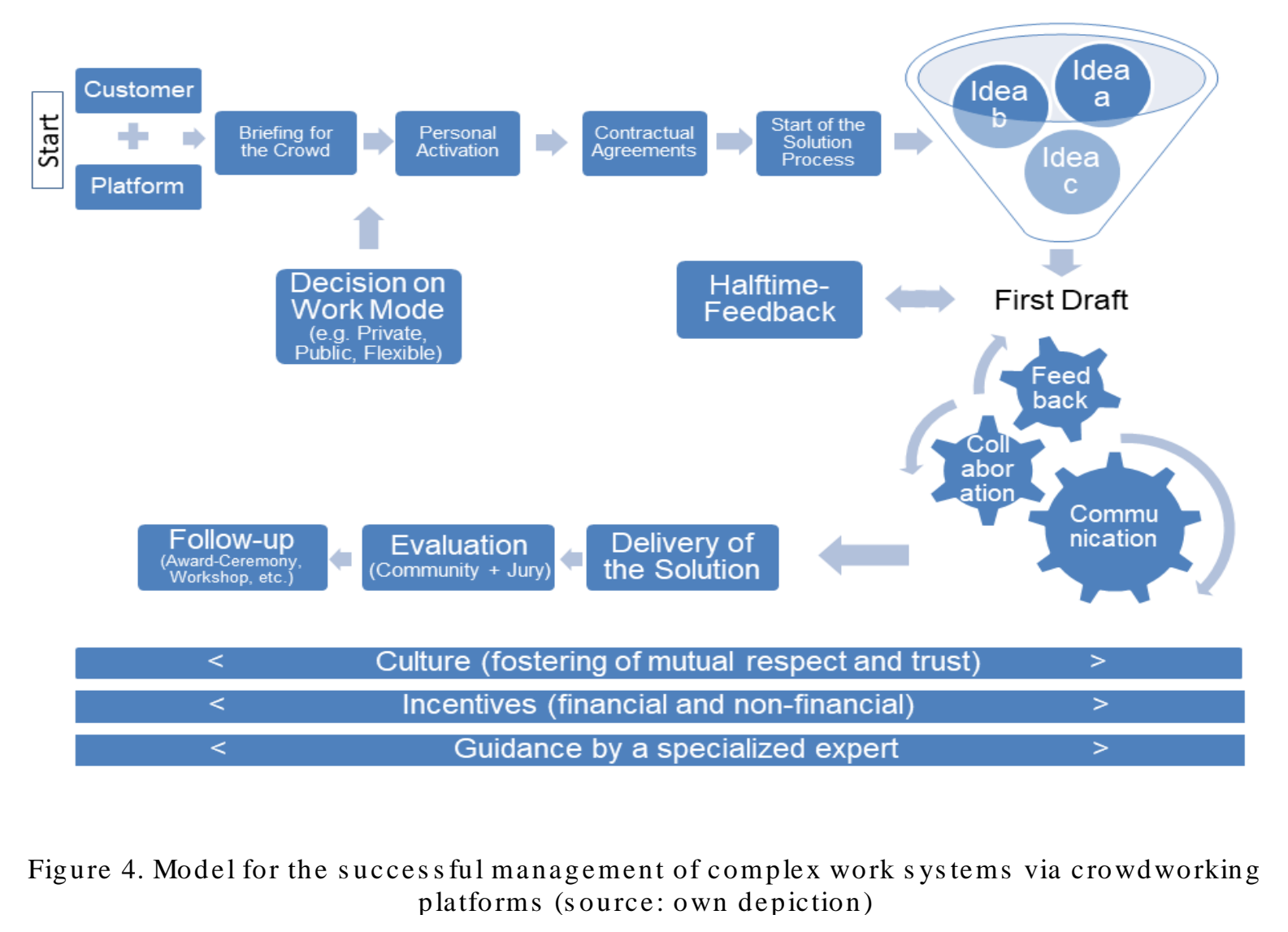


liver products/services for the customer. We on that basis derived and explained several measures for the successful management of complex work systems in general. Finally, we established and visualized the model for the successful management of complex work systems via crowdworking platforms.

With our relevatory single-case study, we provide valuable insights and shed light on phenomena that has not been investigated intensively yet. The approach taken by Deutsche Bank and Jovoto shows what advantages companies can achieve that utilize crowdworking platforms for the processing of their work. Compared to mandating an agency that usually would develop and deliver one or two solutions to the customer, this novel approach generates plenty of diverse solutions in a shorter amount of time and in a more transpartent way. Or to communicate it with the value proposition of Jovoto for its customer that also explains the fact that this market has been fastly growing in the last years:

"We generate solutions beyond the own scope ("outside the box") in a shorter amount of time, cheaper and in a more transparent way. This allows the customer to take better informed decisions about future directions."

Bastian Unterberg, CEO of Jovoto

With our research and the developed model, we deliver insights for both companies that would like to utilize crowd work and operators of crowdworking platforms. These two groups gain valuable insights how to do so, especially how to manage complex work systems via crowdworking platforms. We contribute and help to fill a gap in the respective realms of information systems (IS), organizational theory and especially platform systems. Our research also aims at delivering stimuli for researchers and avenues for future research.

We plan to further investigate this theme in the future. In particular, we will conduct additional case studies with two other companies and two other crowdworking platforms (one from the IT and one from the public transportation area) that include the management of complex work systems to ensure generability of our findings and insights. We will furthermore evaluate and test our findings by conducting a workshop with CLevel executives of several crowdworking platforms.

\section{Acknowledgements}

This paper presents research that was conducted in the context of the project "Challenge cloud and crowd" that is funded by the German Federal Ministry of Education and Research (BMBF) within the program "Innovations for Tomorrow's Production, Services, and Work" (funding number: 02K14A071) and managed by the Project Management Agency Karlsruhe (PTKA).

\section{References}

[1] Alter, S. 2013. Work System Theory: Overview of Core Concepts, Extensions, and Challenges for the Future. Journal of the Association for Information Systems (JAIS) 14, 2, 72-121.

[2] Benner, C., Ed. 2014. Crowdwork - zurück in die Zukunft? Perspektiven digitaler Arbeit. Bund-Verlag $\mathrm{GmbH}$, Frankfurt am Main.

[3] Brynjolfsson, E. and McAfee, A. 2011. Race against the machine. How the digital revolution is accelerating innovation, driving productivity, and irreversibly transforming employment and the economy. Digital Frontier Press, Lexington, Mass.

[4] Eisenhardt, K. M. 1989. Building Theories from Case Study Research. The Academy of Management Review 14, 4, 532-550.

[5] Frey, C. B. and Osborne, M. A. 2013. The Future of Employment: How Susceptible are Jobs to Computerisation? Oxford Martin School Publications.

[6] Kittur, A., Smus, B., Khamkar, S., and Kraut, R. E. 2011. CrowdForge: Crowdsourcing Complex Work. Proceedings of the 24th annual ACM Symposium on User Interface Software and Technology: October 1619, 2011, Santa Barbara, CA/USA.

[7] Kuek, S. C., Paradi-Guilford, C. M., Fayomi, T., Imaizumi, S., and Ipeirotis, P. 2015. The Global Opportunity in Online Outsourcing. The World Bank, Washington.

[8] Leimeister, J. M. and Zogaj, S. 2013. Neue Arbeitsorganisation durch Crowdsourcing. Eine Literaturstudie. Arbeitspapier 287, Düsseldorf.

[9] Moussawi, S. and Koufaris, M. 2015. Working on Low-Paid Micro-Task Crowdsourcing Platforms: An Existence, Relatedness and Growth View. Proceedings of the International Conference on Information Systems (ICIS) 2015.

[10] Mrass, V., Li, M. M., and Peters, C. 2017. Towards a Taxonomy of Digital Work. 25. European Conference on Information Systems (ECIS), Guimarães, Portugal, 2017, 2515-2524.

[11] Mrass, V. and Peters, C. 2017. Crowdworking-Plattformen in Deutschland. Working Paper Series 16. University of Kassel, Kassel.

[12] Mrass, V., Peters, C., and Leimeister, J. M. 2016. New Work Organization through Crowdworking Platforms. A Case Study. Konferenz "Zukunftsprojekt Arbeitswelt 4.0", 19.09.2016, Stuttgart.

[13] Mrass, V., Peters, C., and Leimeister, J. M. 2017. One for All? Managing External and Internal Crowds through a Single Platform - A Case Study. 50th Hawaii International Conference on System Sciences (HICSS), 2017, 4324-4333.

[14] Mrass, V., Peters, C., and Leimeister, J. M. 2017. Von Kunden für Kunden: Crowd Services als Erweiterung der Digital Customer Experience. HMD Praxis der Wirtschaftsinformatik 54, 317.

[15] Yin, R. K. 2014. Case Study Research. Design and Methods. SAGE Publications, Inc., Los Angeles. 